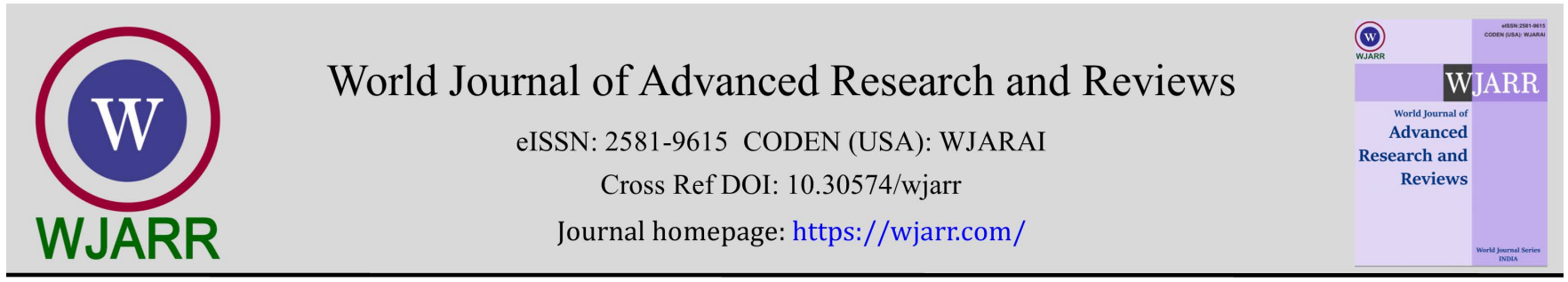

(REVIEW ARTICLE)

Check for updates

\title{
A review on synthesis methods of tricyclic 1,2,3,4-tetrahydrocarbazoles
}

\author{
Nitin Kumar ${ }^{1,}{ }^{*}$, Vinod Kumar ${ }^{2}$ and Yogita Chowdhary 1 \\ ${ }_{1}^{1}$ Sanskar College of Pharmacy and Research (SCPR), Opp. Jindal Pipes Itd, NH-24, Jindal Nagar, Ghaziabad, Uttar Pradesh \\ 201302. \\ 2 OM Sterling Global University, NH-52, Hisar-Chandigarh Road, Hisar, Haryana 125001.
}

World Journal of Advanced Research and Reviews, 2022, 13(01), 160-171

Publication history: Received on 28 November 2021; revised on 04 January 2022; accepted on 06 January 2022

Article DOI: https://doi.org/10.30574/wjarr.2022.13.1.0754

\begin{abstract}
In this review article, we discussed old to new synthetic methods used for the preparation of 1,2,3,4Tetrahydrocarbazole (THCz) based on reported literature. Around the worldwide, various researchers energetically reported new synthetic methods for tetrahydrocarbazoles preparation using conventional method or microwave method or use of catalyst. This review will be helpful to synthetic and medicinal chemist to find selective method for the preparation of 1,2,3,4-Tetrahydrocarbazoles with good percentage yield and less time. This review will also useful to medicinal chemist to design new biologically active tetrahydrocarbazoles based on reported synthetic methods.
\end{abstract}

Keywords: Tetrahydrocarbazole (THcz); Synthesis; Fischer Indole; Microwave (MW)

\section{Introduction}

1,2,3,4-Tetrahydrocarbazole [THCz] is a tricyclic aromatic structure consisting of a five membered pyrrole ring fused with one side benzene ring and other side cyclohexane ring respectively [1-3]. Tetrahydrocarbazole (THCz) structure is majorly present in natural products and biologically active compounds [4-7] (Fig. 1). THCz have received lot of attention in medicinal chemistry and possess a wide variety of potential pharmacological activities such as antiAlzheimer [8], antimicrobial [9], hypoglycemic [10], antifungal [11], anticancer [12], antipsychotic activity [13], and antiemetic [14], anti-inflammatory [15] etc. (Fig. 1).

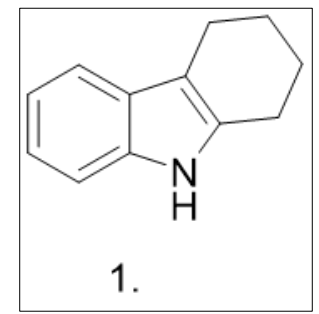

Figure 1 Structure of 1,2,3,4-Tetrahydrocarbazole (1)

A lot of strategy available for the preparation of 1,2,3,4-tetrahydrocarabzole scaffold in literature. However, Fischer indole synthesis approach is most common synthetic method used for the preparation of tetrahydrocarbazole scaffold and also play important role in preparation of various natural products [5, 16-18]. Various research groups synthesized tetrahydrocarbazoles based on Fischer indole method using starting material phenyl hydrazine and cyclohexanone

\footnotetext{
${ }^{*}$ Corresponding author: Nitin Kumar

Sanskar College of Pharmacy and Research (SCPR), Opp. Jindal Pipes ltd, NH-24, Jindal Nagar, Ghaziabad, Uttar Pradesh 201302.

Copyright (C) 2022 Author(s) retain the copyright of this article. This article is published under the terms of the Creative Commons Attribution Liscense 4.0.
} 
using conventional, microwave and catalyst approach. In this review article, we covered synthetic methods of 1,2,3,4tetrahydrocarbazoles based on conventional or microwave or catalyst based on reported review literature. In 2020, Ajit Nangare et al. and co-workers published the review article on topic synthetic derivatives of aromatic carbazole [19]. TY Chaudhari et al. published in detail on topic various synthetic methods to the preparation of tetrahydrocarbazoles [5]. This review will give researchers to idea in short way to find out the preparation of 1,2,3,4-tetrahydrocarbazoles from conventional approach or microwave method or use of catalyst.

\section{Synthetic methods to prepare substituted or unsubstituted tricyclic 1,2,3,4-tetrahydrocarbazoles}

\subsection{Borsche-Drechsel cyclization reaction for the synthesis of 1,2,3,4-tetrahydrocarbazole.}

The acid-catalyzed rearrangement of cyclohexanone phenylhydrazone (2) gives 1,2,3,4-tetrahydrocarbazole (1) (Scheme 1) [20-21].

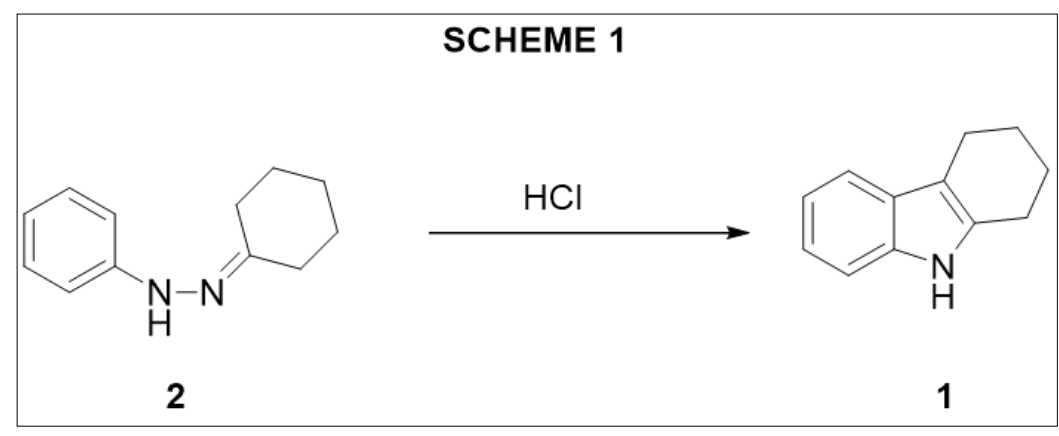

Figure 2 Synthesis of 1,2,3,4-tetrahydrocarbazole (1)

\subsection{Fischer-Borsche reaction for the synthesis of substituted 1,2,3,4-tetrahydrocarbazole.}

The method involves the condensation reaction of 4-methoxy phenyl hydrazine (3) with substituted cyclohexanone (4) with to form arylhydrazone (5) based on Fischer indole synthesis method which further undergoes sigmatropic rearrangement in the presence of acetic acid/HCl gave substituted 1,2,3,4-tetrahydrocarbazole (6) [22, 23] (Scheme 2).

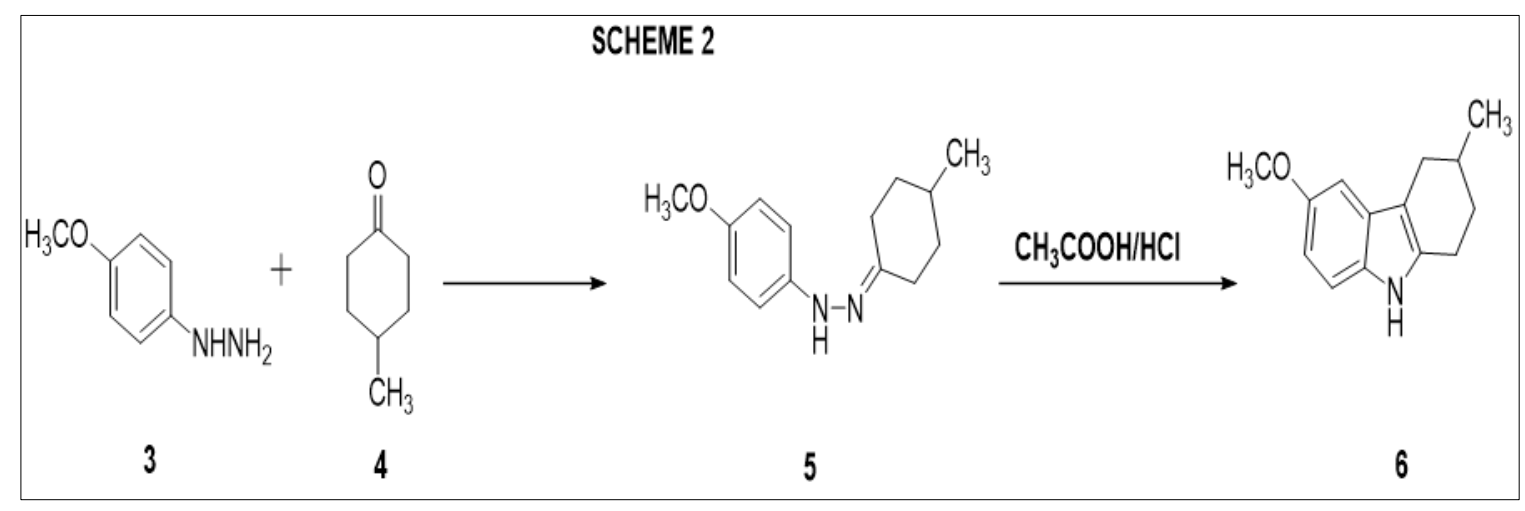

Figure 3 Synthesis of substituted 1,2,3,4-tetrahydrocarbazole (6)

2.3. CU Rogers et al. reported aqueous alcohol- mineral acid method for the preparation of $1,2,3,4$ tetrahydrocarbazole

A mixture of 108 g. phenylhydrazine (7) and 1.5 moles of hydrochloric acid was stirred and refluxed while 98 g. of cyclohexanone (8) was added during one hour gave 1,2,3,4-tetrahydrocarbazole (1). The yield of the reaction was found $95 \%$. [24] (Scheme 3). 


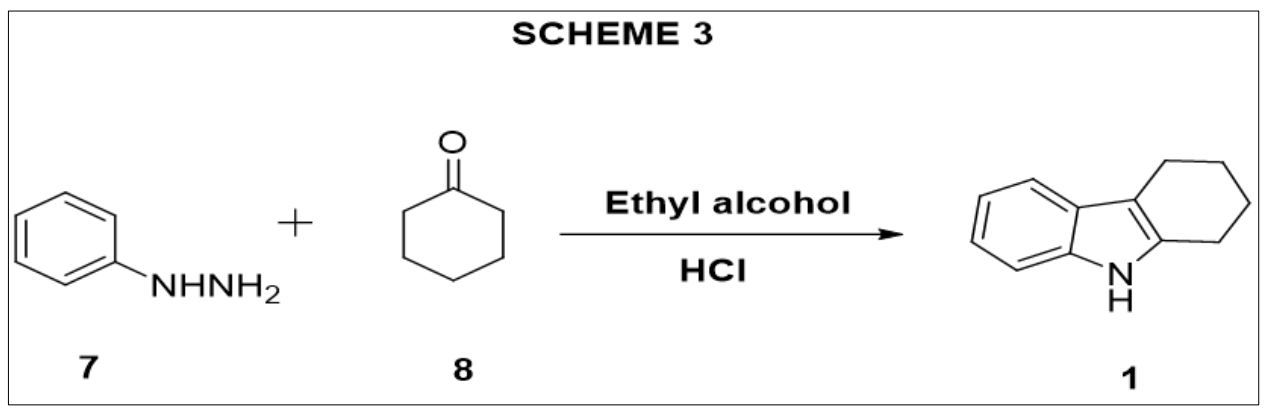

Figure 4 Synthesis of 1,2,3,4-tetrahydrocarbazole (1)

2.4. A Loffler and D. Ginsburg prepared 1,2,3,4-tetrahydrocarbazole from thermal cyclization of the oxime of 2-phenylcyclohexanone.

Heating the starting material oxime of 2-phenylcyclohexanone (9) in aqueous ethanol give 1,2,3,4-tetrahydrocarbazole (1) $[25,26]$.

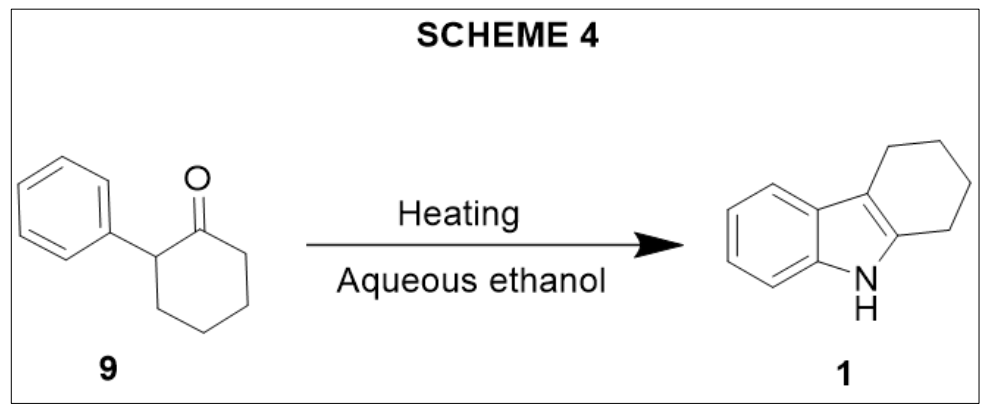

Figure 5 Synthesis of 1,2,3,4-tetrahydrocarbazole (1)

2.5. N. A. Jones and M. L. Tomlins prepared some 1,2,3,4-tetrahydrocarbazoles from various aromatic amines with 2-hydroxycyclohexanone

Condensation reaction of unsubstituted or substituted aromatic amines (10 a-e) with 2-hydroxycyclohexanone (11) with a trace of hydrochloric acid and heated in an oil-bath give some 1,2,3,4-tetrahydrocarbazoles $(1,12-15)($ Scheme $5)$. The yield of the product $(1,12-15)$ was found $37-81 \%$ depends on position and also electron withdrawing or donating group substitution on aromatic amine (10 a-e) [27]

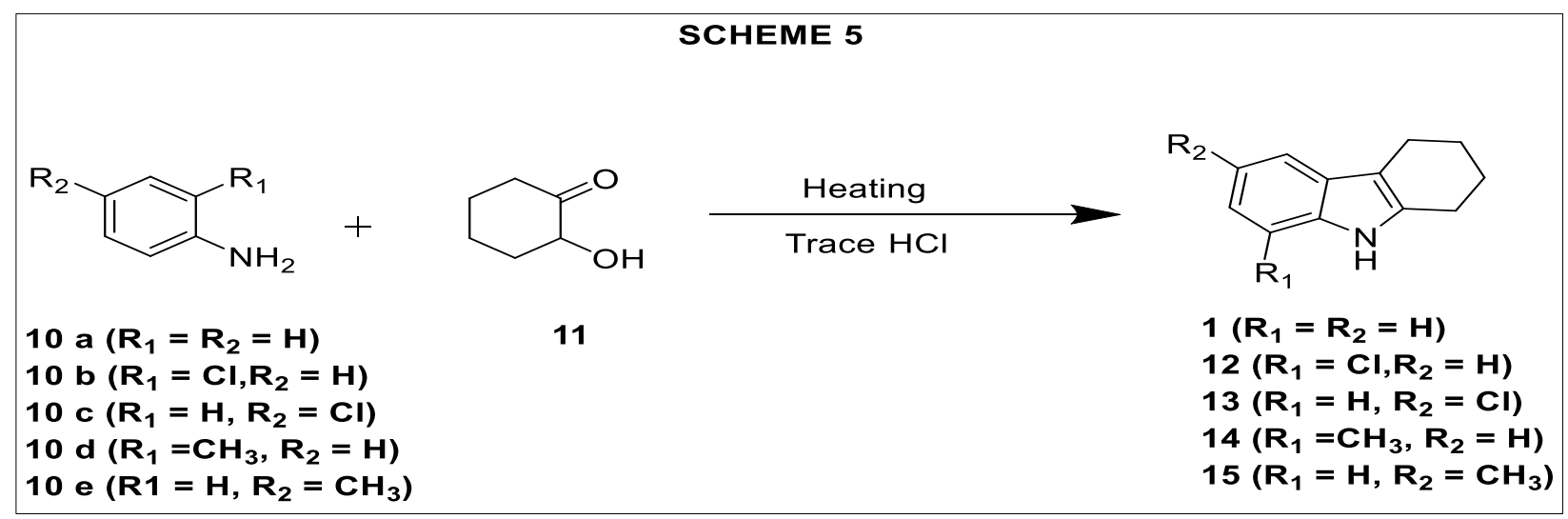

Figure 6 Synthesis of substituted 1,2,3,4-tetrahydrocarbazoles (1, 12-15)

\subsection{K. D. Berlin and co-workers synthesized some 1,2,3,4-Tetrahydrocarbazoles}

Reaction of unsubstituted or substituted phenyl hydrazine (7 or 16) with substituted cyclohexane (17-19) gave substituted `1,2,3,4-tetrahydrocarbazoles (20-23) [27] (Scheme 6). The yield of the product (20-23) was found 28-89\%. 
The yield of 1,2,3,4-tetrahydrocarbazoles (20-23) depends on substitution group on phenyl hydrazine and cyclohexanone ring respectively [28].

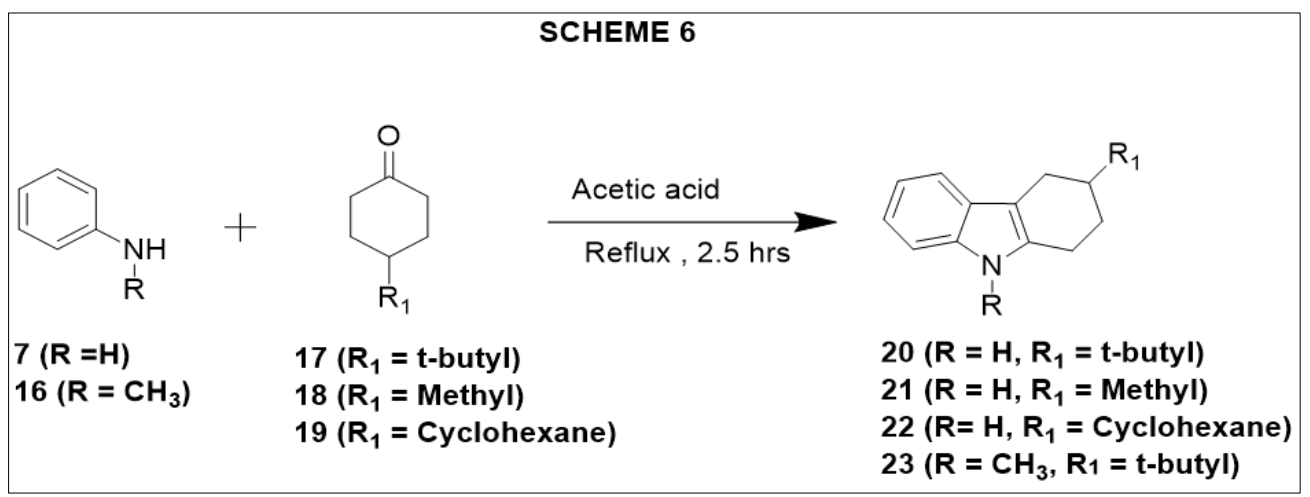

Figure 7 Synthesis of substituted 1,2,3,4-tetrahydrocarbazoles (20-23)

\subsection{Palladium-catalyzed synthesis of 1,2,3,4-tetrahydrocarbazoles}

Heating the reaction mixture of 2-bromo-4,6-dimethylaniline $24 \mathrm{a}-\mathrm{c}$ and cyclohexane-1,3-dione $25 \mathrm{a}$ or dimedone $25 \mathrm{~b}$ gave compounds bromoenaminone 26 a-f. Further reaction of compound 26 a-f with tetrakis[tripbenyIphosphine] palladium [Pd( $\left.\left(\mathrm{PPh}_{3}\right)_{4}\right](2 \mathrm{~mol} \%)$ in hexamethylphosphoramide (HMPA) in the presence of sodium bicarbonate gave the corresponding substituted tetrahydrocarbazoles 27 a-f (Scheme 7). [29]. The yield of the reaction was found $72-77$ \%.

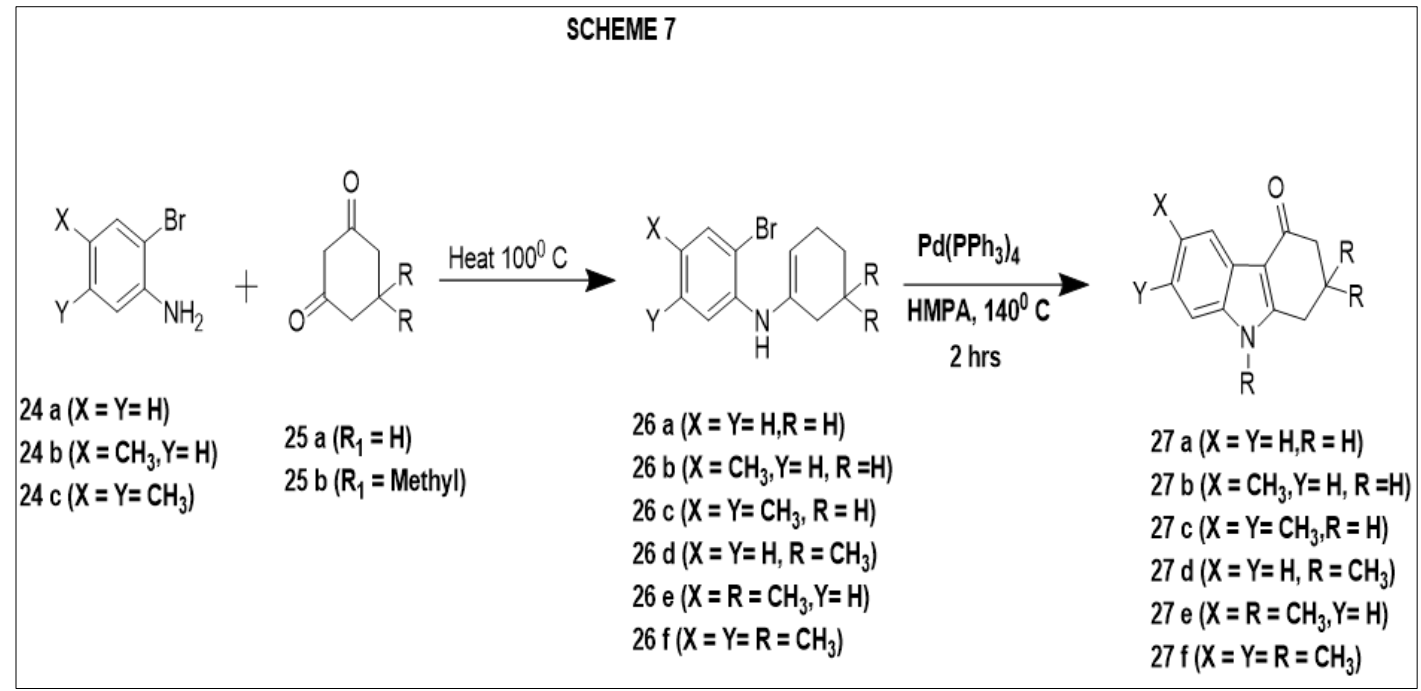

Figure 8 Synthesis of substituted 1,2,3,4-tetrahydrocarbazoles (27 a-f)

\subsection{Regiocontrolled Synthesis of substituted 1,2,3,4-tetrahydrocarbazoles}

The two-step procedure involved the preparation of substituted 1,2,3,4-tetrahydrocarbazoles (31 a-e). First step involves first the regiospecific arylation of silyl enol ethers (28 a-e) with o-nitrophenylphenyliodonium fluoride (29) gave (30 a-e). Reduction of the nitro group on the aromatic ring in compound 30 a-e in the presence of $\mathrm{TiCl}_{3}$ and further spontaneous condensation of the aniline with the keto group gave substituted 1,2,3,4-tetrahydrocarbazoles (31 a-e) (Scheme 8) [30]. The yield of the product (31 a-e) was found 60-88\%. The yield was low found (60\%) in product 31 e due to methoxy substitution in silyl enol ethers $31 \mathrm{e}$. 


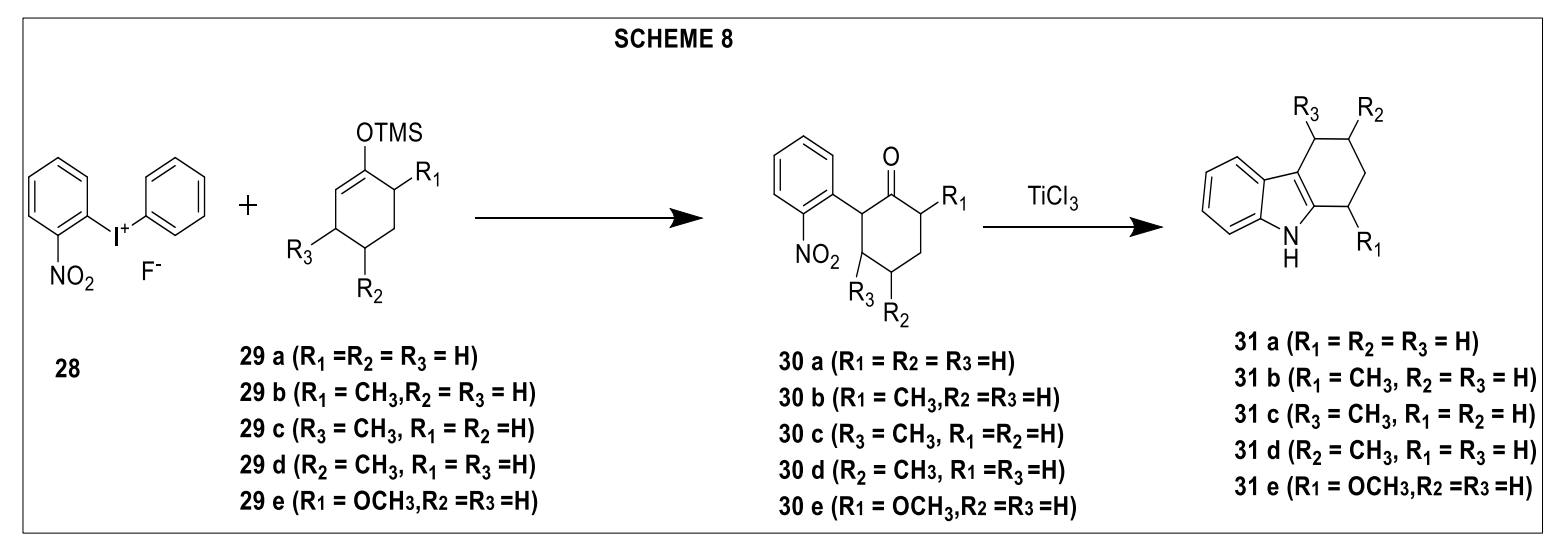

Figure 9 Synthesis of substituted 1,2,3,4-tetrahydrocarbazole (31 a-e)

\subsection{Synthesis of 1,2,3,4-tetrahydrocarbazole using various zeolite catalysts}

D. Bhattacharya et al. and co-workers prepared 1,2,3,4-tetrahydrocarbazoles (33 a-d) using various zeolites catalyst like H-ZSM-12, H-beta, H-mordenite, H-Y, H-ZSM-22, H-EU-1, H-ZSM-5 with various arylhydrazines such as phenylhydrazine (32 a,), o-tolylhydrazine (32 b), p-tolylhydrazine (32 c) and 1,1-diphenylhydrazine (32 d) with cyclohexanone (8) in acetic acid based on Fisher's indole method (Scheme 9) [31]. The yield of the reaction was found 35-69 \%.

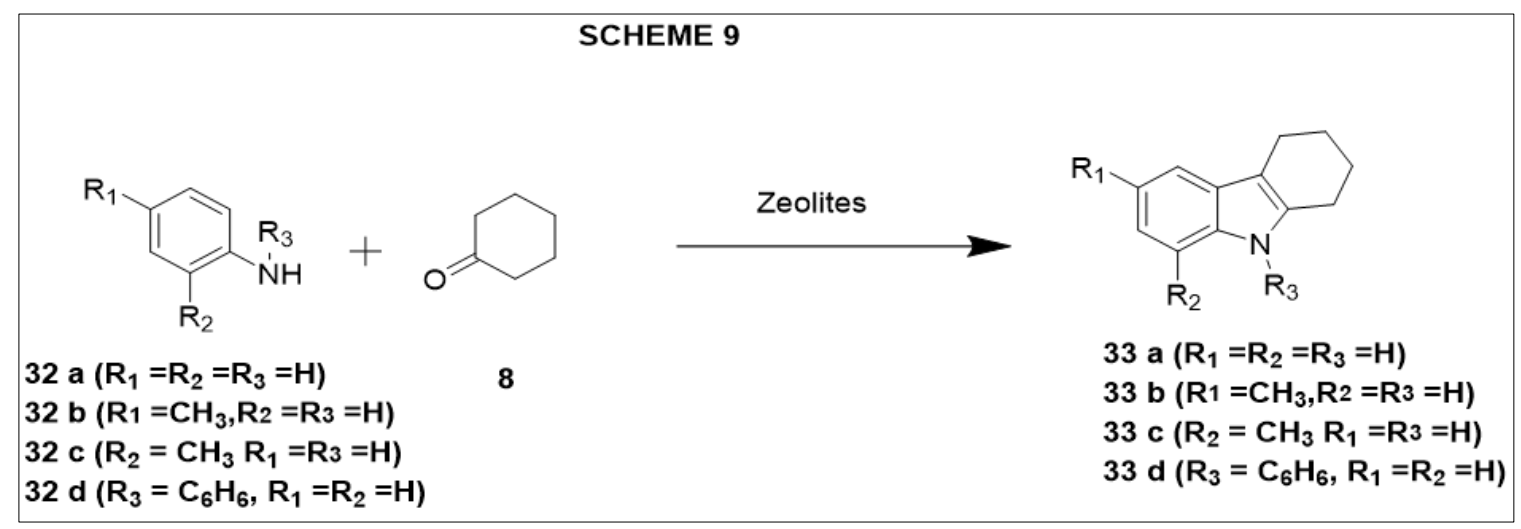

Figure 10 Synthesis of substituted 1,2,3,4-tetrahydrocarbazoles (33 a-d)

\section{MW assisted synthesis of 1,2,3,4-tetrahydrocarbazoles using catalyst $\mathrm{K}-10$ montmorillonite clay}

A. Dhakshinamoorthy et al. reported 1,2,3,4-tetrahydrocarbazole (1) preparation from reaction of phenylhydrazine (7) and cyclohexanone (8) in the presence of solid acid catalyst (namely K-10 montmorillonite clay) was microwave irradiated at $600 \mathrm{~W}$ for 3 minutes in methanol medium [32] (Scheme 10). The yield of the 1,2,3,4-tetrahydrocarbazole (1) was found in conventional method $94 \%$ and microwave method (96\%) respectively.

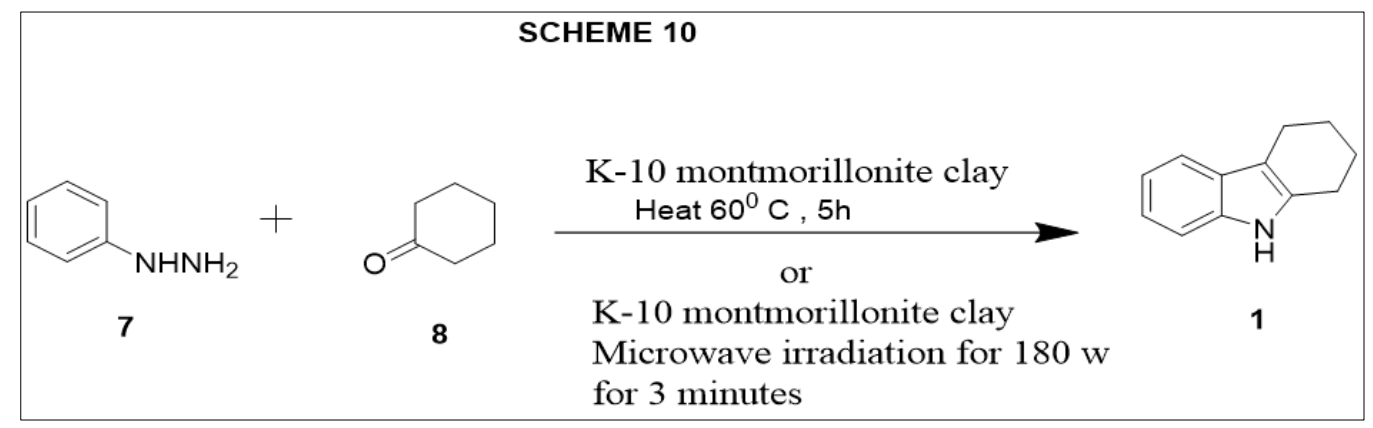

Figure 11 Synthesis of 1,2,3,4-tetrahydrocarbazole (1) 


\subsection{Vera Barbieri and Maria Grazia Ferlin reported MW assisted synthesis of substituted 1,2,3,4- tetrahydrocarbazoles}

Reaction of 2-methoxy-4-nitro-phenylhydrazine with cyclohexanone in the presence of acetic acid was MW irradiation at $100 \mathrm{~W}$ at the temperature $140^{\circ} \mathrm{C}$ give 6-nitro, 8-methoxy 1,2,3,4-tetrahydrocarbazole 35 (Scheme 11) [33]. The yield of the product (35) was found $80 \%$.

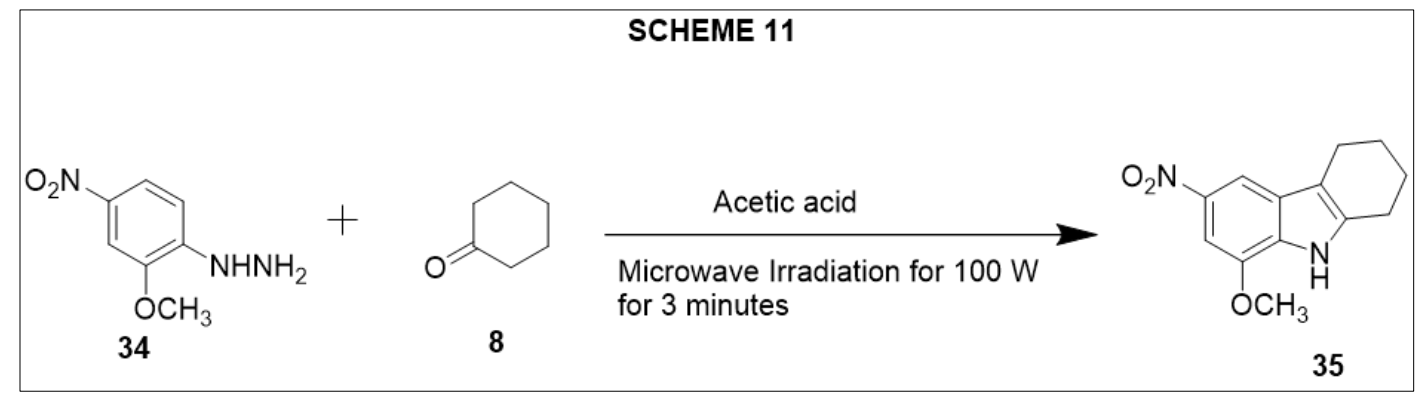

Figure 12 Synthesis of substituted 1,2,3,4-tetrahydrocarbazole (35)

\subsection{MW assisted one pot synthesis of 1,2,3,4-Tetrahydrocarbazoles}

Jing Chen et al. and co-workers reported synthesized 1,2,3,4-tetrahydrocarbazoles (38 a-i) from reaction of starting material 2-bromocyclohexanones (37) and substituted anilines (36 a-i) in molar ratio 1: 3 using different solvents, such as toluene, 1,4-dioxane, ethanol, tert-butanol, and 2-ethoxyethanol under microwave-irradiation conditions also different time [34]. The yield (84\%) was found best for 10 min time using a MW of $325 \mathrm{~W}$ in 2 -ethoxyethanol solvent (Scheme 12).

\begin{tabular}{|c|c|c|c|}
\hline & & SCHEME 12 & \\
\hline $\begin{array}{l}\quad \mathrm{R}_{1} \frac{11}{\mathrm{~N}}+ \\
36 \text { a }\left(\mathbf{R}_{1}=\mathrm{H}\right) \\
36 \mathrm{~b}\left(\mathbf{R}_{1}=\text { p-methyl) }\right. \\
36 \mathrm{c}\left(\mathbf{R}_{1}=3 \text {,4-dimethoxy) }\right. \\
36 \mathrm{~d}\left(\mathbf{R}_{1}=4 \text {-dimethoxyl) }\right. \\
36 \mathrm{e}\left(\mathbf{R}_{1}=2 \text {-methoxy) }\right. \\
36 \mathrm{f}\left(\mathbf{R}_{1}=4 \text {-chloro }\right) \\
36 \mathrm{~g}\left(\mathbf{R}_{1}=3 \text {-chloro }\right) \\
36 \mathrm{~h}\left(\mathbf{R}_{1}=2 \text {-chloro) }\right. \\
36 \mathrm{i} \quad\left(\mathbf{R}_{1}=\text { p-fluoro }\right)\end{array}$ & 37 & $\begin{array}{l}\text { 2-Ethoxyethanol } \\
\text { MW, N2 atmosphere } \\
10 \text { minutes }\end{array}$ & $\begin{array}{l}38 \text { a }\left(R_{1}=H\right) \\
38 \mathrm{~b}\left(R_{1}=\text {-methyl }\right) \\
38 \mathrm{c}\left(\mathbf{R}_{1}=3,4 \text {-dimethoxy) }\right. \\
38 \mathrm{~d}\left(\mathbf{R}_{1}=4 \text {-dimethoxyl) }\right. \\
38 \mathrm{e}\left(\mathbf{R}_{1}=2 \text {-methoxy }\right) \\
38 \mathrm{f}\left(\mathbf{R}_{1}=4 \text {-chloro }\right) \\
38 \mathrm{~g}\left(\mathbf{R}_{1}=3 \text {-chloro }\right) \\
38 \mathrm{~h}\left(\mathbf{R}_{1}=2 \text {-chloro }\right) \\
38 \mathrm{i}\left(\mathbf{R}_{1}=\text { p-fluoro }\right)\end{array}$ \\
\hline
\end{tabular}

Figure 13 Synthesis of substituted 1,2,3,4-tetrahydrocarbazole (38 a-i)

\subsection{Synthesis of 1,2,3,4-tetrahydrocarbazoles from 2-(2-nitrophenyl)-2-cyclohexene-1-ones}

Tricia L. Scott et al. and coworkers reported synthesis of 1,2,3,4-tetrahydrocarbazoles (1, 1a-1e) from reduction of 2(2-nitrophenyl)-2-cyclohexene-1-ones (39 a-f) using palladium on carbon under 1 atm of hydrogen gas at ambient temperature [35] (Scheme 13). The yield of the reaction was found 62-94\%. 


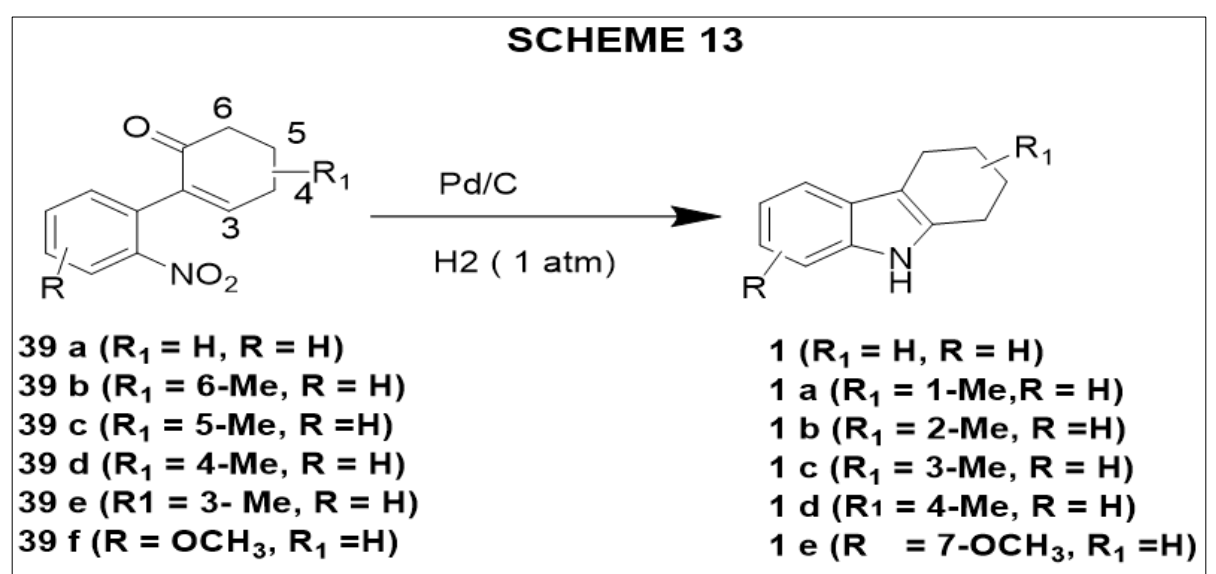

Figure 14 Synthesis of substituted 1,2,3,4-tetrahydrocarbazole (1-1e)

\subsection{Synthesis of substituted 1,2,3,4-tetrahydrocarabzoes using Fischer idolization method}

T. Surendiran and co-workers reported the synthesized 1,2,3,4-tetrahydrocarabzoes (41) from the reaction of substituted phenylhydrazine (40) with cyclohexanone (8), with catalytic amount of glacial acetic acid and trifluoroacetic acid (1:3) was under ultrasound irradiations using Fischer idolization method [36] (Scheme 14). The yield of the reaction was found $77-92 \%$

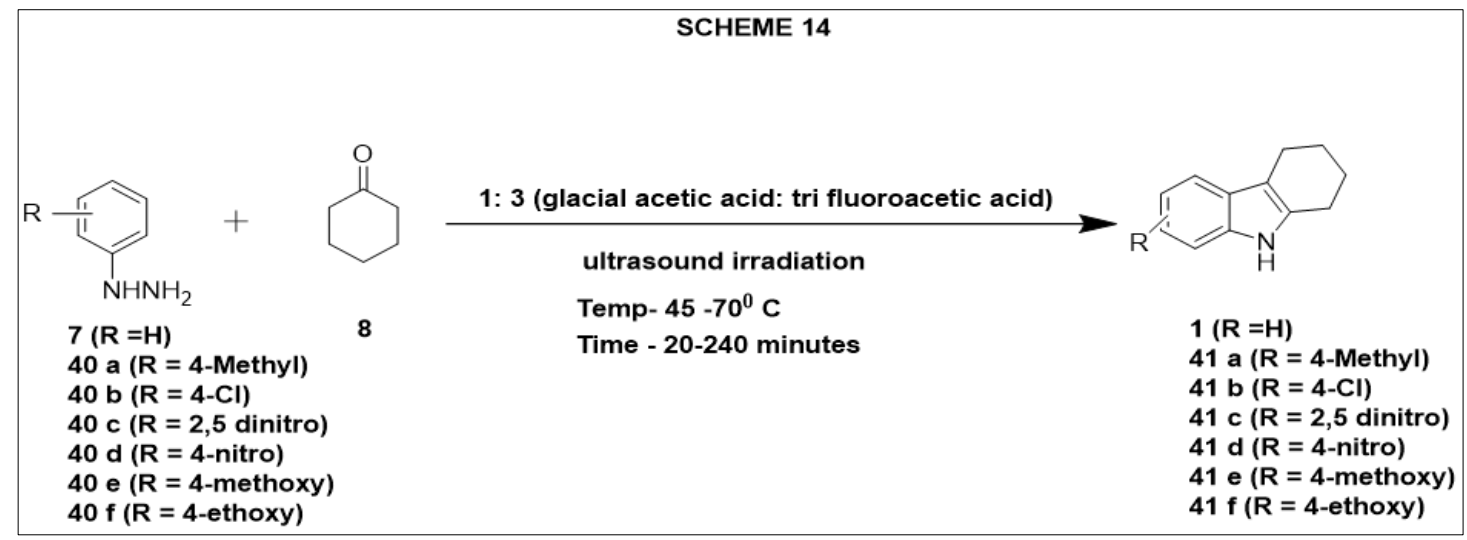

Figure 15 Synthesis of substituted 1,2,3,4-tetrahydrocarbazoles (1, 41 a-f)

\subsection{Synthesis of substituted 1,2,3,4-tetrahydrocarbazoles using ceric ammonium nitrate (CAN)}

Reaction of substituted phenylhydrazine hydrochlorides (7, 42 a-e) with cyclohexanone (8) using ceric ammonium nitrate (CAN) via known Fischer indole synthesis method [37]. The yield of the reaction was found 85-95 \%. (1, 43 a-e) (Scheme 15).

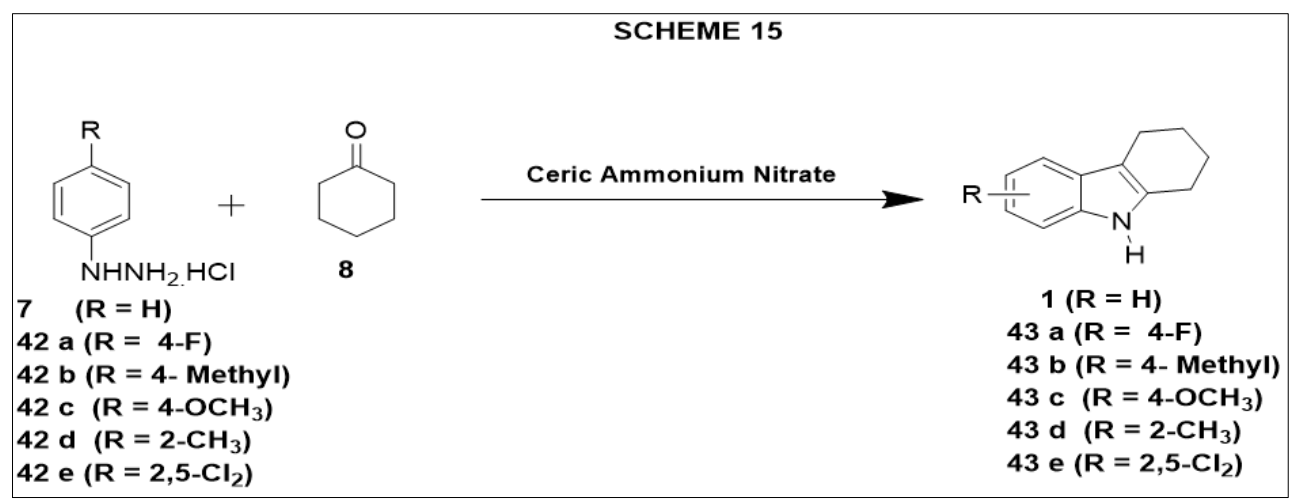

Figure 16 Synthesis of substituted 1,2,3,4-tetrahydrocarbazoles (1, 43 a-c) 


\subsection{MW assisted Fischer Indole Synthesis of 1,2,3,4-tetrahydrocarbazoles}

Reaction of substituted phenylhydrazine (7, $44 \mathrm{a}, 44 \mathrm{~b}$ ) cyclohexanone (8) and zinc chloride were MW at $600 \mathrm{~W}$ for 3 min, give 1,2,3,4-tetrahydrocarbazole with $76 \%$ yield. However, when zinc chloride was replaced with p-toluene sulfonic acid (p-TSA), the reaction yield found excellent 91-93\% of 1, 2, 3, 4-tetrahydrocarbazoles (1, 45 a and 45 b) [38]

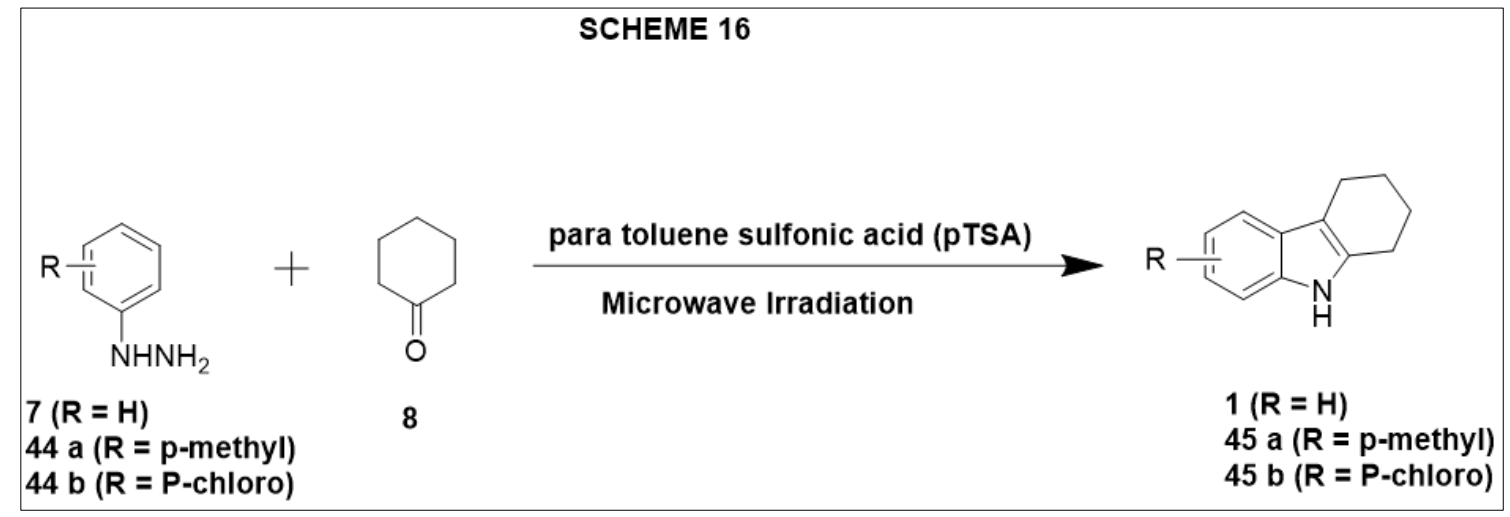

Figure 17 Synthesis of substituted 1,2,3,4-tetrahydrocarbazoles (1, 45 a-b)

\subsection{N. Campbell and E. B. McCall prepared some 1,2,3,4-Tetrahydrocarbazoles from 2-Chlorocyclohexenone}

Condensation reaction of 2-chlorocycohexanone (46) with aromatic primary or secondary amines (47 a-g) gives substituted 1,2,3,4-tetrahydrocarbazoles (48 a-g) [39] (48 a-g) (Scheme 17). However, aromatic primary or secondary amines contains at least one unsubstituted ortho-position. The yields of products were found of 30-60\%. Reaction was found less effective when 2-Chlorocycloohexenone was replaced with 2-bromocycloohexenone

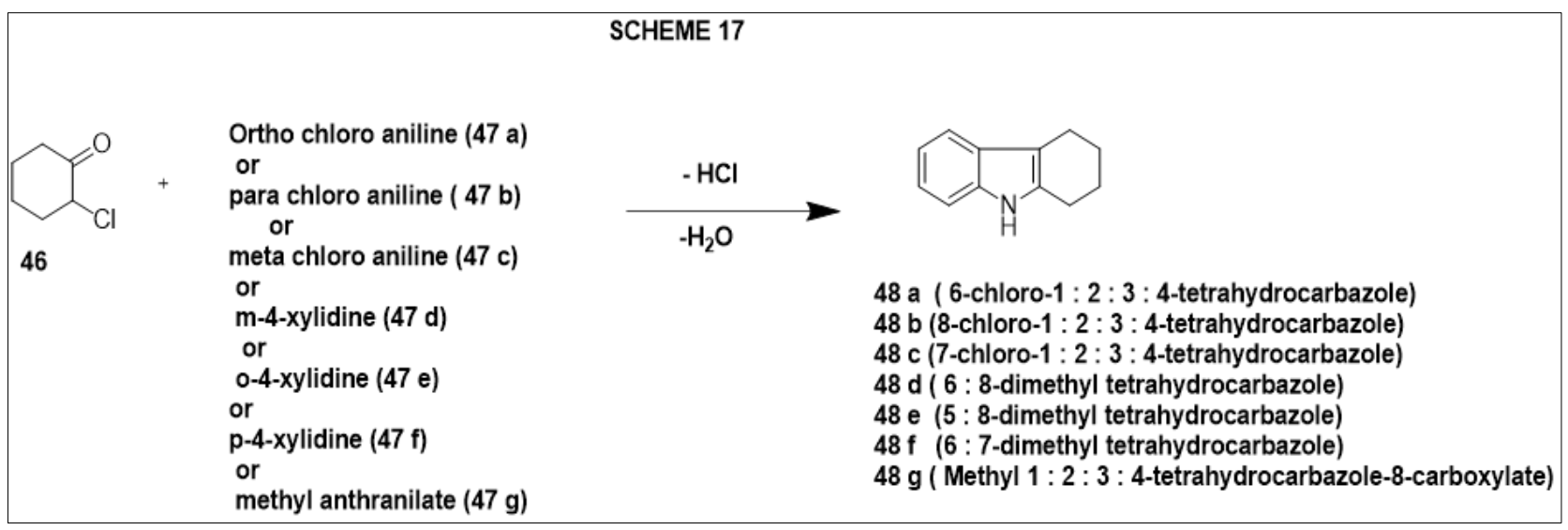

Figure 18 Synthesis of substituted 1,2,3,4-tetrahydrocarbazoles (48 a-g)

\subsection{Synthesis of substituted 1,2,3,4-Tetrahydrocarbazoles by Petasis reaction}

Reaction of substituted phenyl hydrazine (49) with substituted aryl boronic acid (50) and glyoxylic acid (51) in dichloromethane solvent was stirred at room temperature gave substituted N-Boc phenyl hydrazine derivatives (52) which further reacted cyclohexanone (8) afforded substituted 1,2,3,4-Tetrahydrocarbazoles compounds (53). [40] (Scheme 19) 


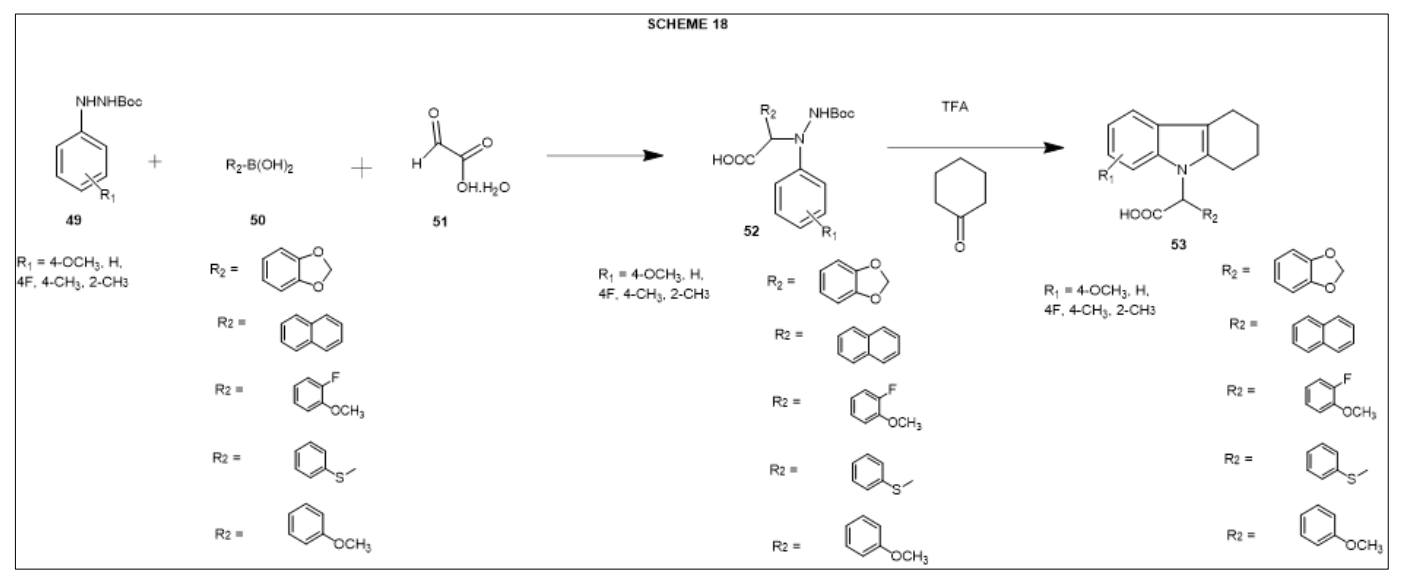

Figure 19 Synthesis of substituted 1,2,3,4-tetrahydrocarbazoles (53)

\subsection{Synthesis of substituted 1,2,3,4,9-tetrahydro-1H-carbazoles and 2,3,4,9-tetrahydro-1H-carbazoles using bmim (BF4) ionic liquid}

Reaction of substituted phenylhydrazine (54) and substituted cyclohexanone (55), using a 1-butyl-3methylimidazolium tetrafluoroborate [bmim (BF4)] ionic liquid afforded 1,2,3,4,9-tetrahydro-1H-carbazole (56 a) and substituted 2,3,4,9-tetrahydro-1H-carbazoles $56 \mathrm{~b}$-j (Scheme 19) [41]. The yield of the reaction was found 29-49\%.

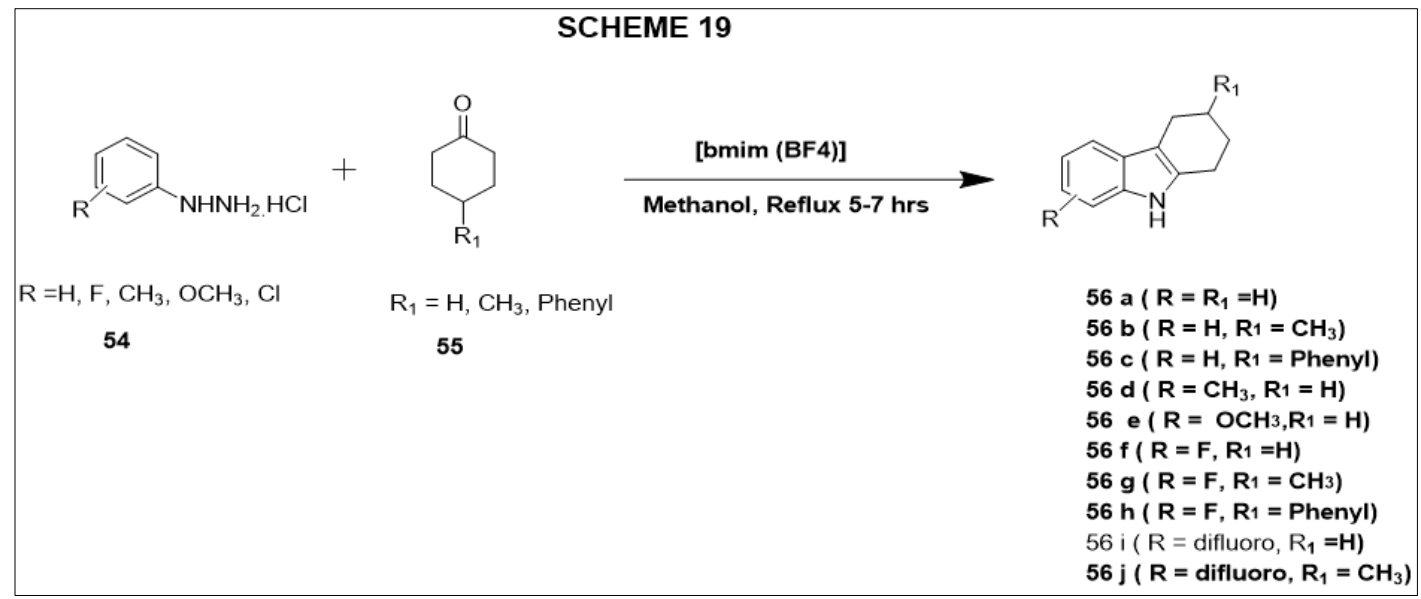

Figure 20 Synthesis of substituted 1,2,3,4-tetrahydrocarbazoles and 2,3,4,9-tetrahydro-1H-carbazoles (56 a-j)

\section{Synthesis of 1-0xo-1,2,3,4-tetrahydrocarbazoles}

An acid catalyzed ring closure of 3-indolebutyric acid (57) in the presence of polyphosphoric acid (PPA) gave 1-0xo-1, 2, 3, 4-tetrahydrocarbazoles (58) [42, 43]. The yield of the reaction was found $84 \%$.

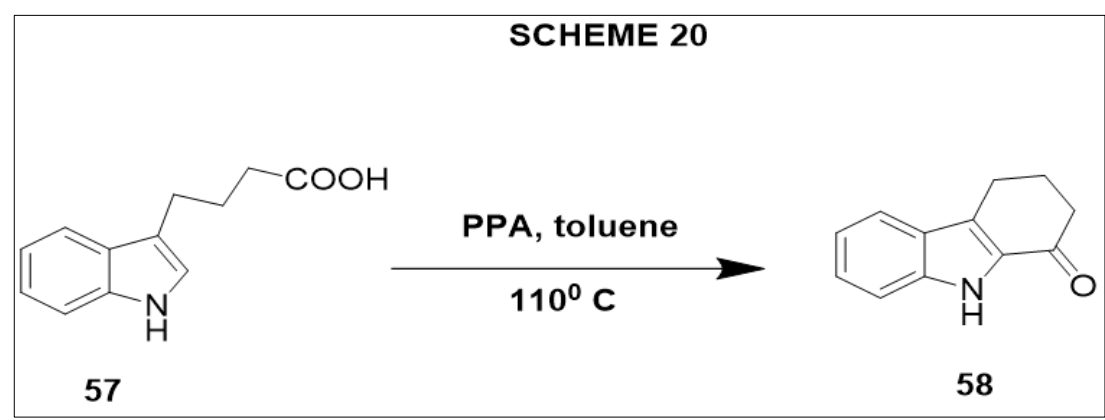

Figure 21 Synthesis of 1-0xo-1,2,3,4-tetrahydrocarbazoles 


\subsection{Synthesis of substituted 1-0xo-1,2,3,4-tetrahydrocarbazoles}

Reaction of substituted phenyl hydrazine hydrochlorides (59) with substituted 2-aminocyclohexanone hydrochlorides (60) based on Fischer indole synthesis method in mild condition $2 \mathrm{~N} \mathrm{NaOH}$ and $80 \%$ acetic acid give substituted 1-0xo1,2,3,4-tetrahydrocarbazoles (61) (Scheme 21).[44] The yield of the reaction was found 45-94 \%.

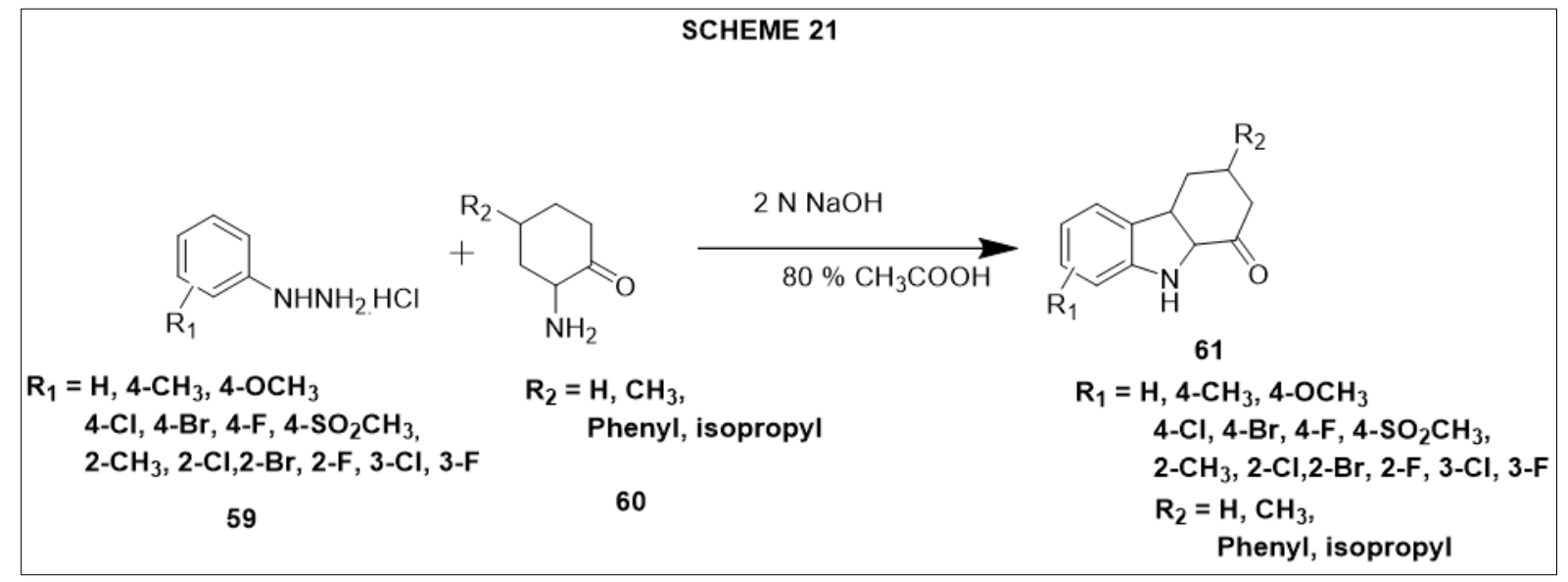

Figure 22 Synthesis of substituted 1,2,3,4-tetrahydrocarbazoles (61)

\section{Conclusion}

In this review article, we covered various synthetic method for the preparation of 1,2,3,4-tetrahydrocarabzoles based on conventional, microwave and catalyst approach. Now day's use of catalyst is become popular and it is very useful in the synthesis of complex natural products. Catalyst gives a short way to prepare complex or multistep molecule. However, availability and cost of catalyst is very important to synthetic and medicinal chemist. Generally, most of the preparation of 1,2,3,4-tetrahydrocarabzoles based on Fischer indole synthesis method in review literature. Substitution like hydrogen and electron donating or electron withdrawing group due to inductive or mesomeric effect plays a major role for the preparation of 1,2,3,4-tetrahydrocarabzoles in good yield and less time in review literature [1,5,34,45,46]. This review gives a detail idea of availability and selection of various synthetic method available for preparation of 1,2,3,4-tetrahydrocarabzoles based on conventional, microwave and catalyst approach with percentage yield.

\section{Compliance with ethical standards}

\section{Acknowledgments}

Dr. Nitin Kumar and Yogita Chowdhary are thankful to Sanskar College of Pharmacy and Research, Ghaziabad for support for work.

\section{Disclosure of conflict of interest}

Authors have declared none conflict of interest in this review article.

\section{References}

[1] Chakraborty S, Panda P. A Comprehensive Overview of the Synthesis of Tetrahydrocarbazoles and its Biological Properties. Mini-Reviews in Organic Chemistry. 1 Sep 2021; 18(6): 709-18.

[2] Luthra PM, Kumar N. Progress and development of C-3, C-6, and N-9 position substituted carbazole integrated molecular hybrid molecules as potential anticancer agents. Mini Reviews in Medicinal Chemistry. 21 May 2021;21(19);2929-2956.

[3] Kumar N, Singh KK and Luthra PM. A review on anticancer potential of some pyranocarbazole alkaloids and its derivatives. International Journal of Advance Research. 2021; 9(6): 874-883. 
[4] Kumar N, Kumar R, Nemaysh V, Lal N, Luthra PM. Bis ((1, 4-dimethyl-9 H-carbazol-3-yl) methyl) amine-mediated anticancer effect triggered by sequence-specific cleavage of DNA leading to programmed cell death in the human U87 cell line. RSC advances. 2016; 6(72): 67925-40.

[5] Chaudhari TY, Tandon V. Recent approaches to the synthesis of tetrahydrocarbazoles. Organic \& Biomolecular Chemistry. 2021; 19(9): 1926-39.

[6] Kumar N, Kumar R, Nemaysh V, Lal N, Luthra PM. Bis ((1, 4-dimethyl-9 H-carbazol-3-yl) methyl) amine-mediated anticancer effect triggered by sequence-specific cleavage of DNA leading to programmed cell death in the human U87 cell line. RSC advances. 2016; 6(72): 67925-40.

[7] Schmidt AW, Reddy KR, Knölker HJ. Occurrence, biogenesis, and synthesis of biologically active carbazole alkaloids. Chemical reviews. 13 Jun 2012; 112(6): 3193-328.

[8] Honarnejad K, Daschner A, Gehring AP, Szybinska A, Giese A, Kuznicki J, Bracher F, Herms J. Identification of tetrahydrocarbazoles as novel multifactorial drug candidates for treatment of Alzheimer's disease. Translational psychiatry. Dec 2014; 4(12): e489-.

[9] Al-Mohson A, Mohammed Z. Synthesis of novel pyrazole derivatives containing tetrahydrocarbazole, antimicrobail evaluation and molecular properties. Eurasian Chemical Communications. 1 Jun 2021; 3(6): 42534.

[10] Wang LL, Du Y, Li SM, Cheng F, Zhang NN, Chen R, Cui X, Yang SG, Fan LL, Wang JT, Guo B. Design, synthesis and evaluation of tetrahydrocarbazole derivatives as potential hypoglycemic agents. Bioorganic Chemistry. 1 Oct 2021; 115: 105172.

[11] Wang W, Dong G, Gu J, Zhang Y, Wang S, Zhu S, Liu Y, Miao Z, Yao J, Zhang W, Sheng C. Structure-activity relationships of tetrahydrocarbazole derivatives as antifungal lead compounds. MedChemComm. 2013; 4(2): 353-62.

[12] Saravanabhavan M, Ebenazer AF, Murugesan V, Sekar M. Synthesis, Spectroscopic Characterization and Biological Evaluation of 1-(4'-Hydroxybenzamido)-Imine-1, 2, 3, 4-Tetrahydrocarbazole Derivatives. Journal of Advanced Physics. 1 Mar 2017; 6(1): 30-40.

[13] Rotella DP, McFarlane GR, Greenfield A, Grosanu C, Robichaud AJ, Denny RA, Feenstra RW, Núñez-García S, Reinders JH, van der Neut M, McCreary A. Tetrahydrocarbazole-based serotonin reuptake inhibitor/dopamine D2 partial agonists for the potential treatment of schizophrenia. Bioorganic \& medicinal chemistry letters. 1 Oct 2009; 19(19): 5552-5.

[14] Xu Q, Liu T, Tian R, Li Q, Ma D. Synthesis and antiemetic activity of 1, 2, 3, 9-tetrahydro-9-methyl-3-(4-substitutedpiperazin-1-ylmethyl)-4 H-carbazol-4-one derivatives. Frontiers of Chemistry in China. Mar 2009; 4(1): 63-8.

[15] Sakinala P, Chikhale R, Tajne M. Design, Synthesis and Pharmacological Evaluation of Some Novel Tetrahydrocarbazoles as Potential COX-2 Inhibitors. Letters in Drug Design \& Discovery. 1 Apr 2018; 15 (4): 43749.

[16] Robinson B. The Fischer indole synthesis. Chemical reviews. 1 Aug 1963; 63(4): 373-401.

[17] Hughes DL. Progress in the Fischer indole reaction. A review. Organic preparations and procedures international. 1 Dec 1993; 25(6): 607-32

[18] Heravi MM, Rohani S, Zadsirjan V, Zahedi N. Fischer indole synthesis applied to the total synthesis of natural products. RSC advances. 2017; 7(83): 52852-87.

[19] Nangare A, Lodha GS, Chavan AN, Matkar MG. Synthetic derivative of aromatic carbazole ring. World Journal of Pharmaceutical Research. 2018 Dec 8; 1: 389-94.

[20] Drechsel E. Borsche-Drechsel cyclization. J. Prakt. Chem. 1858; 38(2): 69-72.

[21] Li JJ. Borsche-Drechsel cyclization. In Name Reactions 2014; (68-69). Springer, Cham.

[22] Borsche WI. Ueber Tetra-und Hexahydrocarbazolverbindungen und eine neue Carbazolsynthese. (Mitbearbeitet von. A. Witte und W. Bothe.). Justus Liebigs Annalen der Chemie. 1908; 359(1-2): 49-80.

[23] Fischer E, Jourdan F. Ueber die hydrazine der brenztraubensäure. Berichte der deutschen chemischen Gesellschaft. Jul 1883; 16(2): 2241-5.

[24] Rogers CU, Corson BB. One-Step Synthesis of 1, 2, 3, 4-Tetrahydrocarbazole and 1, 2-Benzo-3, 4dihydrocarbazole. Journal of the American Chemical Society. Nov 1947; 69(11): 2910-1. 
[25] Amiel Y, Löffler A, Ginsburg D. Studies in the Alicyclic Series. Part II. 1 Synthesis and Reactions of 2Phenylcyclopent-2-enone. Journal of the American Chemical Society. Jul 1954; 76(14): 3625-8.

[26] Löffler A, Ginsburg D. A New Synthesis of Carbazoles. Nature. Oct 1953; 172(4383): 820.

[27] Jones NA, Tomlinson ML. 837. Indoles derived from aromatic amines and 2-hydroxy-ketones. The synthesis of 7acetyl-2: 3: 4': 5'-tetraphenylpyrrolo (2': 3'-4: 5)-indole. Journal of the Chemical Society (Resumed). 1953; 41146.

[28] Berlin KD. Synthesis of 1, 2, 3, 4-Tetrahydrocarbazoles with Large Group-Aromatization to Carbazoles. InProceedings of the Oklahoma Academy of Science. 5 Feb 1967; (215-220).

[29] Wang HM, Chou HL, Chen LC. Palladium-Catalyzed Synthesis of Tetrahydrocarbazoles. Journal of the Chinese Chemical Society. Jun 1995; 42(3): 593-5.

[30] Iwama T, Birman VB, Kozmin SA, Rawal VH. Regiocontrolled synthesis of carbocycle-fused indoles via arylation of silyl enol ethers with o-nitrophenylphenyliodonium fluoride. Organic letters. 26 Aug 1999; 1(4): 673-6.

[31] Bhattacharya D, Gammon DW, Van Steen E. Synthesis of 1, 2, 3, 4-tetrahydrocarbazole over zeolite catalysts. Catalysis letters. Aug 1999; 61(1): 93-7.

[32] Dhakshinamoorthy A, Pitchumani K. Facile clay-induced Fischer indole synthesis: A new approach to synthesis of 1, 2, 3, 4-tetrahydrocarbazole and indoles. Applied Catalysis A: General. 18 Sep 2005; 292: 305-11.

[33] Barbieri V, Ferlin MG. Microwave-assisted one-pot synthesis of substituted tetrahydrocarbazole and 8, 9, 10, 11tetrahydro-7H-pyrido [a] carbazoles. Tetrahedron letters. 20 Nov 2006; 47(47): 8289-92.

[34] Chen J, Hu Y. Microwave-Assisted One-Pot Synthesis of 1, 2, 3, 4-Tetrahydrocarbazoles. Synthetic communications. 1 Jun 2006; 36(11): 1485-94.

[35] Scott TL, Burke N, Carrero-Martínez G, Söderberg BC. Synthesis of 1, 2, 3, 4-tetrahydrocarbazoles and related tricyclic indoles. Tetrahedron. 29 Jan 2007; 63(5): 1183-90.

[36] Surendiran T, Balasubramanian S, Sivaraj D. Improved Synthesis of 1, 2, 3, 4 tetrahydrocarbazoles Under Ultrasonic Irradiation. Organic Chemistry: An Indian Journal. Dec 2008; 4(9-11): 478-81.

[37] Varma PP, Sherigara BS, Mahadevan KM, Hulikal V. Efficient and straightforward synthesis of tetrahydrocarbazoles and 2, 3-dimethyl indoles catalyzed by CAN. Synthetic Communications@. 16 Dec 2008 ; 39(1): 158-65.

[38] Creencia EC, Tsukamoto M, Horaguchi T. One-pot-one-step, microwave-assisted Fischer indole synthesis. Journal of Heterocyclic Chemistry. Sep 2011; 48(5): 1095-102.

[39] Campbell N, McCall EB. 558. The preparation of tetrahydrocarbazoles from 2-chloro-cyclo hexanone. Journal of the Chemical Society (Resumed). 1950: 2870-4.

[40] Neogi S, Roy A, Naskar D. One-Pot synthesis of new substituted 1, 2, 3, 4-tetrahydrocarbazoles via petasis reaction. Journal of combinatorial chemistry. 13 Sep 2010; 12(5): 617-29.

[41] Eduque Jr RM, Creencia EC. Microwave-assisted Fischer indole synthesis of 1, 2, 3, 4-tetrahydrocarbazole using pyridinium-based ionic liquids. Procedia Chemistry. 1 Jan 2015; 16: 413-9.

[42] Ishizumi K, Shioiri T, Yamada SI. Studies in the Indole Series. II. A General Synthesis of Cycloalkan [b] indolones. Chemical and Pharmaceutical Bulletin. 25 Jun 1967; 15(6): 863-72.

[43] Maertens F, Toppet S, Hoornaert GJ, Compernolle F. Incorporation of an indole-containing diarylbutylamine pharmacophore into furo [2, 3-a] carbazole ring systems. Tetrahedron. 14 Feb 2005; 61(7): 1715-22.

[44] Sheng R, Shen L, Chen YQ, Hu YZ. Convenient and efficient synthesis of 1-oxo-1, 2, 3, 4-tetrahydrocarbazoles via Fischer indole synthesis. Synthetic Communications®. 25 Feb 2009; 39(6): 1120-7.

[45] Mishra CB, Sharma D, Prakash A, Kumari N, Kumar N, Luthra PM. Design and synthesis of (4E)-4-(4substitutedbenzylideneamino)-3-substituted-2, 3-dihydro-2-thioxothiazole-5-carbonitrile as novel A2A receptor antagonists. Bioorganic \& medicinal chemistry. 2013 Oct 1;21(19):6077-83.

[46] Sadiq Z, Akbar Hussain E, Naz S. Carbazole Derivatives by Microwave Promoted Protocols: A Mini Review. MiniReviews in Organic Chemistry. 2017 Dec 1;14(6):469-88. 